\title{
Ensinando ciências: Um enfoque em meio ambiente e energia
}

\author{
Teaching science: A focus on environment and energy
}

Gilberto Dias de Alkimin'1, Carolina Buso Dornfeld ${ }^{2}$

UNESP-Sorocaba, UNESP - Ilha Solteira

\begin{abstract}
Resumo
A sociedade contemporânea buscou um maior conforto em suas atividades cotidianas, sem se preocupar demasiadamente com a forma com que este seja alcançado. Essa busca, com o passar do tempo provocou crises, como exemplo a energética. Além disso, o meio ambiente sofre constantes prejuízos com a falta de percepção da população, inicialmente no descarte inadequado de produtos e no uso exagerado de outros. Com isso a Educação Ambiental surge como tentativa de conscientização sobre essas questões possibilitando à população uma maneira de formar uma opinião mais crítica sobre as questões ambientais. Assim, o objetivo deste estudo foi elaborar diferentes atividades teórico-práticas com a finalidade aproximar os alunos das questões ambientais. As atividades ocorreram na forma de encontros semanais com os alunos nos quais adotou-se a pluralidade metodológica para o trabalho com os temas. Com isso pode-se dizer que existe sim uma certa consciência, não por parte de todos os alunos, mas de sua maioria, sobre a importância do meio ambiente e sua conservação.

Palavras-chave: Energias renováveis. Fabricação de sabão. Papel reciclado.
\end{abstract}

\begin{abstract}
Contemporary society sought comfort with their daily activities without worrying too with the way that this is achieved. This seeking, with the passage of time has caused crises, such as the energy. Moreover, the environment suffers constant damage with lack of perception of the population, initially in the improper disposal of products and the overuse of others. With this Environmental Education emerges as an attempt to raise awareness about these issues enabling the population a way to form an opinion on the most critical environmental issues. Therefore, the objective of this study was to develop different theoretical and practical activities in order to approach the students of environmental issues. The activities took place in the form of weekly meetings with students in which we adopted the methodological plurality to work with the themes. With this we can say that yes there is a certain awareness, not by all students, but mostly about the importance of the environment and its conservation.
\end{abstract}

Keywords: Renewable energies. Manufacture of soap. Recycled paper. 


\section{Introdução}

O quadro socioambiental que caracteriza as sociedades contemporâneas revela que a relação estabelecida entre os humanos e o meio ambiente está causando impactos cada vez mais complexos, tanto em termos quantitativos, quanto qualitativos, nas condições de vida das populações e na capacidade de suporte planetária com vistas a garantir a qualidade de vida das futuras gerações. $\mathrm{O}$ conceito de desenvolvimento sustentável surge no contexto do enfrentamento da crise ambiental, configurada na degradação sistemática de recursos naturais e nos impactos negativos desta degradação sobre a saúde humana. Duas correntes interpretativas se sobressaem neste processo. Uma primeira - econômica e técnico-científica - que propõe a articulação do crescimento econômico e a preservação ambiental, influenciando mudanças nas abordagens do desenvolvimento econômico, notadamente a partir dos anos 1970. A segunda, relacionada com a crítica ambientalista ao modo de vida contemporâneo, e que se difunde a partir da Conferência de Estocolmo em 1972, momento no qual a questão ambiental ganha visibilidade pública e se coloca a dimensão do meio ambiente na agenda internacional (JACOBI, 2006).

À medida que se observa cada vez mais dificuldade de manter-se a qualidade de vida nas cidades e regiões, é preciso fortalecer a importância de garantir padrões ambientais adequados e estimular uma crescente consciência ambiental, centrada no exercício da cidadania e na reformulação de valores éticos e morais, individuais e coletivos, numa perspectiva orientada para o desenvolvimento sustentável (JACOBI, 2003).

Sendo assim, a preocupação em discutir as questões ambientais no processo de escolarização de crianças e jovens remonta a década de 1990, porém o marco do surgimento do debate ambiental é a década de 1960. Em 1962 Raquel Carson com o seu livro "Primavera Silenciosa", lançou de modo enfático, as primeiras bases para que todos os cientistas, crianças, jovens, políticos e professores dirigissem seus olhares e suas ações para a defesa dos ecossistemas do planeta (BOVO, 2007), por isso ensinar ciências com ênfase em questões ambientais torna-se algo de grande necessidade para o momento, esse assunto em alguns casos é tratado como Educação Ambiental (EA) e Sato (2004) afirma que dentre os objetivos da EA encontra-se a responsabilidade ambiental, que nada mais é do que a reconhecimento do ser humano como principal protagonista para determinar e garantir a manutenção do planeta. Portanto, a EA busca a partir da análise do comportamento da comunidade escolar, uma mudança do paradigma de desenvolvimento capitalista, que tem como alicerce o consumo intenso e contínuo fora dos limites de suporte do planeta (GUIMARÃES, 2005).

\section{Objetivos}

O presente trabalho tem por objetivo aproximar os alunos do Ensino Fundamental de temas como reciclagem de óleo e papel, consumo e geração de energia, conservação do meio ambiente e sustentabilidade e dar-lhes condições de realizar uma análise sobre os padrões atuais, formando assim, opiniões críticas.

\section{Materiais e métodos}

Este trabalho fez parte do Projeto Usina Ecoelétrica e integra os projetos desenvolvidos junto ao Programa Núcleos de Ensino-PROGRAD-UNESP e PROEX-UNESP, na Faculdade de Engenharia de Ilha Solteira (FEIS-UNESP). As atividades foram desenvolvidas com os alunos do $6^{\mathbf{o}}$ ano do Ensino Fundamental de uma escola particular localizada em Ilha Solteira (SP).

A realização do convite aos alunos se deu na forma de uma visita a sala de aula de interesse e a explanação do projeto. O projeto foi oferecido em horário contrário ao das aulas regulares, tendo assim a sua adesão facultativa pelos alunos, obtendo a participação de 10 a 17 alunos nos diferentes 
encontros. As atividades foram desenvolvidas no LECBio (Laboratório de Ensino de Ciências e Biologia - UNESP, Campus de Ilha Solteira) em seis encontros (um por semana), com duração média de 2 horas, sendo os mesmos divididos em atividades teóricas e práticas. No mesmo momento do convite foram distribuídas caixas de papelão por todas as salas da escola para que os alunos descartassem o papel nesse recipiente, que futuramente seria utilizado em uma das atividades do projeto.

As atividades foram desenvolvidas de acordo com o Pluralismo Metodológico proposto por Laburú et al (2003), aliando aulas teóricas com atividades práticas diversificadas com o objetivo de proporcionar um melhor entendimento do conteúdo ao maior número de alunos. Para um melhor entendimento da proposta, segue-se uma breve descrição das atividades realizadas:

$1^{\text {a }}$ semana: Os alunos foram apresentados: ao projeto, a cronograma das atividades, as metodologias e aos temas a serem abordados. Na sequência foi aplicado um questionário inicial (QP) contendo duas perguntas sobre o tema “Energias renováveis x não renováveis". Por fim, ocorreu a realização de uma aula teórica com a introdução ao tema energia, sendo discutidos, energia hidroelétrica, termoelétrica e proveniente do petróleo. Além disso, foi fornecido aos alunos uma garrafa PET de 2L, etiquetada e com identificação do projeto, para coleta de óleo de cozinha utilizado em casa para realização de atividades futuras.

$2^{\text {a }}$ semana: Continuidade ao tema energia abordando a energia eólica, solar e biomassa. Para ilustração na parte teórica foram confeccionados cata-ventos com cartolina pelos próprios alunos e a demonstração de um forno solar caseiro, feito a partir de caixa de papelão, tinta preta e papel alumínio. Foi aplicado o questionário final (QF) com as mesmas perguntas feitas em QP.

$3^{\text {a }}$ semana: Nessa semana o tema abordado foi biodiesel, discutindo as diferentes origens vegetais. Houve a realização de uma prática laboratorial onde foi demonstrado aos alunos a produção de biodiesel e glicerina a partir de óleo vegetal, seguindo os procedimentos de Moreno (2007), sendo executada pela equipe do projeto em conjunto com os alunos, a fim de desenvolver nestes a capacidade de realizar e analisar experimentos em ciências. No final da atividade foi aplicado um questionário (QB) sobre o tema da aula.

$4^{\text {a }}$ semana: Nessa atividade os aspectos abordados foram a reciclagem e a reutilização com enfoque no óleo de cozinha e os prejuízos decorrentes de seu uso e descarte incorretos. A atividade foi finalizada com o preparo de sabão caseiro utilizando o óleo coletado pelos alunos com a garrafa PET que lhes foi dada na primeira semana do projeto.

5 ${ }^{\text {a }}$ semana: O conteúdo ministrado contemplava a problemática do papel, quanto ao uso e acúmulo, bem como também os prejuízos causados ao meio ambiente, levando-se em consideraçãoas questões econômicas. A parte prática constou da confecção de papel reciclado com o papel coletado nas caixas espalhadas nas salas de aula nas escolas no dia da apresentação do projeto, que foram recolhidas e trazidas ao LECBio.

$6^{\text {a }}$ semana: Foi realizado uma roda-de-conversa, no qual os alunos levantaram suas percepções e opiniões. Nesse dia eles desenvolveram uma atividade artística decorando o papel reciclado produzido na aula anterior para a elaboração de bloquinhos de papel. Além disso, foi aplicado um questionário (QJ) aos alunos denominado de "Jogo do telefone", adaptado de Antunes (1996).

A análise das respostas dos questionários foi realizada de acordo coma análise qualitativa textual proposta por Moraes (2007), já que essa forma de análise trabalha com informações em forma de texto, onde realiza--se uma rigorosa leitura na tentativa de descrever e interpretá-los as respostas. Envolve a identificação e isolamento de enunciados dos materiais estabelecidos, categorização desses enunciados, utilizando como base de sua construção o sistema de categorias desenvolvido na análise.

Deve-se salientar que as respostas transcritas no trabalho mantêm a identidade do aluno em sigilo, os mesmo são denominados por letras. Além disso, erros gramaticais e ortográficos foram mantidos, sendo as respostas transcritas na íntegra. 


\section{Resultados e discussão}

Como na metodologia, para a melhor compreensão dos resultados os mesmos serão expostos por encontros semanais:

$1^{\text {a }}$ semana: Os alunos (17) responderam a duas perguntas no QP, a primeira na qual foi lhes pedido que relacionasse as fontes de energia com seus significados, isso porque, os padrões atuais de produção e consumo de energia são baseados nas fontes fósseis, o que gera emissões de poluentes locais, gases de efeito estufa e põem em risco o suprimento de longo prazo no planeta. É preciso mudar esses padrões estimulando as energias renováveis, e, nesse sentido, o Brasil apresenta uma condição bastante favorável em relação ao resto do mundo (GOLDEMBERG; LUCON, 2007).

O s dados obtidos são apresentados na Tabela 1, comparando QP e QF. Houve um aumento na porcentagem de acerto acerca da energia hidrelétrica, biomassa, eólica e termelétrica. E um decréscimo no que se refere a definições de energia solar e petróleo.

Tabela 1. Respostas dos alunos em porcentagem de acerto acerca da questão: Relacione as fontes de energia com seus significados.

\begin{tabular}{lcc} 
Tipos de energia & $\begin{array}{c}\text { Porcentagem de respostas } \\
\text { corretas }(\mathrm{QP}-17 \text { alunos) }\end{array}$ & $\begin{array}{c}\text { Porcentagem de respostas } \\
\text { corretas (QF - 12 alunos) }\end{array}$ \\
\hline Solar & 82,3 & 75,0 \\
\hline Petróleo & 70,6 & 58,3 \\
\hline Hidrelétrica & 58,8 & 75,0 \\
\hline Biomassa & 52,9 & 66,3 \\
\hline Eólica & 23,5 & 75,0 \\
\hline Termelétrica & 11,8 & 58,3 \\
\hline
\end{tabular}

Fonte: Dados obtidos nos QP e QF.

Visto a crise energética atual e importância do tema ainda é escasso dados de trabalhos de EA que tenham como foco esse tema.

A segunda pergunta solicitava que separassem as fontes de energia citadas na primeira pergunta em energias renováveis e energias não renováveis. A tabela 2 ilustra os resultados obtidos quanto às fontes renováveis, a qual podemos observar que houve um acréscimo de respostas corretas no QF em relação às fontes de energia renováveis. e a tabela 3 quanto às fontes não renováveis. Na tabela 2

Tabela 2. Respostas dos alunos em porcentagem acerca da questão: Das fontes de energia da questão anterior, quais você acha que são renováveis.

\begin{tabular}{|c|c|c|c|}
\hline $\begin{array}{l}\text { Respostas } \\
\text { renováveis }\end{array}$ & - Fontes & $\begin{array}{c}\text { Porcentagem de respostas } \\
\qquad(\mathrm{QP}-17 \text { alunos })\end{array}$ & $\begin{array}{c}\text { Porcentagem de respostas } \\
\text { (QF }-12 \text { alunos })\end{array}$ \\
\hline Hidrelétrica* & & 35,3 & 58,33 \\
\hline Solar* & & 29,4 & 58,33 \\
\hline Eólica* & & 23,5 & 66,66 \\
\hline Biomassa* & & 23,5 & 16,66 \\
\hline Termelétrica & & 17,65 & 8,33 \\
\hline Petróleo & & 11,75 & 0 \\
\hline
\end{tabular}

* Respostas tidas como certas para a respectiva pergunta.

Fonte: Dados obtidos nos QP e QF do presente projeto.

Quando questionados a respeito das fontes não renováveis os alunos apresentaram bom conhecimento sobre o assunto, devido ao aumento da porcentagem das respostas certas em QF sendo observado que nenhum aluno assinalou as alternativas relativas às energias eólica e solar, por fim, 
pensando que a energia pode ser bem ou mal utilizada e levar a desperdícios inúteis, é plausível citar a importância da informação e de intervenções que atuem no nível da educação (MARQUES, 2007).

Tabela 3. Respostas dos alunos em porcentagem acerca da questão: Das fontes de energia da questão anterior, quais você acha que são não renováveis.

\begin{tabular}{lcc}
$\begin{array}{c}\text { Respostas - Fontes não } \\
\text { renováveis }\end{array}$ & $\begin{array}{c}\text { Porcentagem de respostas } \\
(\mathrm{QP}-17 \text { alunos })\end{array}$ & \begin{tabular}{c} 
Porcentagem de respostas \\
\cline { 3 - 3 }
\end{tabular} \\
\hline Petróleo* & 41,2 & $(\mathrm{QF}-12$ alunos $)$ \\
\hline Biomassa & 29,4 & 58,33 \\
\hline Termelétrica* & 23,4 & 16,66 \\
\hline Hidrelétrica & 23.4 & 41,66 \\
\hline Eólica & 17,65 & 8,33 \\
\hline Solar & 5,9 & 0 \\
\hline
\end{tabular}

${ }^{*}$ Respostas tidas como certas para a respectiva pergunta.

Fonte: Dados obtidos nos QP e QF do presente projeto.

2a semana: Houve a aplicação do QF, os quais as respostas já foram utilizadas a título de comparação na construção das Tabelas 1, 2 e 3. Após a aula expositiva ocorreu a exposição de um forno solar e a montagem de cata-ventos pelos alunos

$3^{a}$ semana: Após trabalhar o conteúdo teórico sobre biodiesel e a realização do experimento, ocorreu a aplicação do QB, respondido por 10 alunos.

A primeira pergunta questionava aos alunos o que eles acharam da aula prática e porque, onde $100 \%$ dos alunos disseram que as mesmas eram consideradas boas. $70 \%$ dos alunos disseram que aprendem mais/melhor com as aulas práticas, $50 \%$ referiram-se a aprender mais divertindo-se e $10 \%$ mencionaram que aprenderam mais porque fizeram o que viram na teoria.

Na segunda pergunta foi solicitado aos alunos que explicassem em uma frase a importância das aulas práticas, obtendo-se exemplos tais como: Aluno A: "Que a aula prática você aprende se divertindo."; Aluno B: "Com as aulas práticas aprendemos as coisas, realizando-as."; Aluno C: "Que facilita o aprendisado."

Na pergunta seguinte eles responderam "O que é biodiesel", e 90\% dos alunos disseram que biodiesel é um combustível biodegradável.

Por fim em QB os alunos tiveram que explicar as vantagens do biodiesel com as suas próprias palavras. A maioria (70\%) enfocou a questão ambiental do uso do biodiesel dizendo que a maior vantagem é que ele poliu menos, indo de encontro ao proposto por Oliveira e Aquino (2010), onde devemos nos preocupar com a falta de combustíveis fósseis (derivados de petróleo) e a poluição por eles causada. Os outros alunos, $10 \%$ disseram que a vantagem está relacionada ao abastecimento e $20 \%$ não sabem ou não responderam. Para exemplificação temos as seguintes frase: Aluno A: "Que polui menos o meio ambiente do que os outros."; Aluno B: "O biodiesel e menos poluente que os derivados do petróleo causa menos impactos ambientais."; Aluno C: "Ele não polui muito a natureza."

$4^{\mathrm{a}}$ semana: No decorrer da aula pode-se observar o interesse dos alunos pelo tema trabalhado e tiveram grande participação durante as semanas com a coleta de óleo em suas residências, bem como no momento do preparo do sabão.

5 a semana: Durante a confecção do papel reciclado artesanal os alunos estiveram motivados e se sentiram estimulados com a realização dessa atividade. Deve-se considerar que o papel utilizado para essa confecção foi obtido das caixas de papelão que foram depositadas na escola no início do projeto. Além disso, o papel confeccionado por eles seria utilizado para compor a capa de bloquinhos de papel.

$6^{\text {a }}$ semana: Realizou-se uma roda-de-conversa com os alunos com a finalidade de estimular o pensamento referente aos conteúdos abordados durante o projeto, para assim finalizar as atividades. Após, os alunos decoraram as capas para os bloquinhos de papel e por último foi aplicado o "Jogo do 
Telefone" (QJ), uma conversa telefônica entre Ana e Paulo e que foi respondido por 14 alunos. No primeiro contato Ana pede a Paulo para lhe explicar o que foi ensinado nas últimas aulas, $71,4 \%$ dos alunos responderam que foi sobre papel reciclado e sabão seguido de $14,2 \%$ que falaram do papel reciclado e deram a explicação dos procedimentos para a confecção do mesmo, seguindo-se sobre a fala e explicação de papel reciclado e sabão em conjunto $(7,15 \%)$ e somente papel reciclado $(7,15 \%)$.

Continuando a ligação telefônica, foi pedido a eles que explicassem como foi realizada a produção do sabão, sendo que $100 \%$ dos alunos citaram os materiais utilizados e o procedimento adotado para essa atividade. Para exemplificar seguem duas respostas elaboradas pelos alunos: Aluno A: "Primeiro colocamos o óleo usado que recolhemos em uma bacia e depois adicionamos água, desinfetante e soda. Mexemos bastante e usamos luvas, o resto foram os professores que fizeram."; Aluno B: "Os professores usaram óleo usado, soda. Depois colocamos desinfetante para deixar cheiroso,".

Na questão seguinte Ana pede que seja explicada a importância da reutilização do óleo de cozinha usado que apesar de ser parte ínfima do lixo da população é capaz de causar muitos impactos ambientais (OLIVEIRA; AQUINO, 2010), 42,8\% dos alunos responderam que reduz/não causa a poluição, seguido pela citação sobre a utilização para elaboração do sabão $(21,45 \%)$ (tabela 4$)$.

Tabela 4. Respostas dos alunos em porcentagem acerca da questão: Qual a importância da reutilização do óleo de cozinha?

\begin{tabular}{cc} 
Respostas & Porcentagem de alunos \\
\hline Reduz/ não causa a poluição & 42,85 \\
\hline Utilização para fazer sabão & 21,45 \\
\hline Não entope a pia & 14,3 \\
\hline $\begin{array}{c}\text { Dizem saber a importância, } \\
\text { mas não explicaram }\end{array}$ & 7,15 \\
\hline Reaproveitamento & 7,15 \\
\hline $\begin{array}{c}\text { "Faltaram" na explicação/não } \\
\text { responderam }\end{array}$ & 21,45 \\
\end{tabular}

Fonte: Dados obtidos do QJ

Seguindo no telefonema foi pedido aos alunos que explicassem como foi realizada a aula da produção do papel reciclado sendo que a reciclagem surgiu como uma maneira de reintroduzir no sistema uma parte da matéria (e da energia), que se tornaria lixo (LIMA, 2007). Os alunos citaram os materiais utilizados e os procedimentos (85,7\%). Abaixo estão apresentadas duas respostas elaboradas pelos alunos: Aluno A: "Nós colocamos papel no balde e colocamos no liquidificador colocamos tinta e batemos, depois colocamos numa penera e depois colocamos no jornal para secar."; Aluno B: "Ah, essa foi muito divertida. Usamos o papel usado em uma bacia com água e picamos ele. Colocamos no liquidificador e adicionamos tinta. Depois de batermos a mistura em uma tela e tiramos o essesso de água e o viramos em um jornal e o deixamos secar."

Logo depois eles foram questionados sobre a importância da reciclagem do papel, já que a reciclagem e a reutilização de papel, além de ajudar a solucionar o problema do acúmulo de lixo, também diminui a devastação florestal (RIBEIRO et al, 2007). A resposta mais citada $(57,15 \%$ dos alunos) referia-se à diminuição dos impactos ambientais/corte de árvores, seguida por 28,6\% enfocando a importância para a reutilização do material (tabela 5). 
Tabela 5. Respostas dos alunos em porcentagem acerca da questão: Qual a importância da reciclagem do papel usado?

\begin{tabular}{cc} 
Respostas & Porcentagem dos alunos \\
\hline $\begin{array}{c}\text { Diminuição de impactos } \\
\text { ambientais/corte de árvores }\end{array}$ & 57,15 \\
\hline Reutilizar & 28,6 \\
\hline Diminuição do lixo & 21,45 \\
\hline Não sabem/não responderam & 7,15 \\
\hline \multicolumn{2}{c}{ Fonte: Dados obtidos de QJ }
\end{tabular}

A próxima pergunta foca ainda mais a questão ambiental, isso porque pergunta diretamente se os alunos acreditam que a reciclagem contribui para a diminuição de impactos ambientais, onde $92,85 \%$ disseram que sim, que a reciclagem diminui os impactos ambientais, indo de encontro ao que Lima (2007) diz, onde na atualidade percebemos a preocupação de algumas pessoas em relação a questão da reciclagem de papel, uma vez que esta implica em fatores de grande proporção como conservação das florestas, economia de recursos como a água e tantos outros e os alunos citam para exemplificar frases tais como: Aluno A: "Acredito, pois ajuda as árvores."; Aluno B: "Sim, você está ajudando a salvar o planeta."; Aluno C: "Claro que sim, um deles é diminuir a quantidade de árvores cortadas para a produção de papel."

\section{Conclusões}

O atual modelo socioeconômico nos leva a pensar sobre o modo que estamos agindo perante o meio ambiente e isso faz com que cada vez mais a educação ambiental seja necessária e se torne parte do cotidiano, principalmente o cotidiano escolar, fase em que mais se aprende e se torna semeador das novas ideias e dos novos conteúdos aprendidos.

Sendo assim, a educação ambiental crítica tomou destaque na sociedade e através desse projeto que obteve/apresentou grandes resultados, podemos assim, concluir a veracidade dessa informação e tirarmos uma principal conclusão:

- existe sim uma certa consciência, não por parte de todos os alunos, mas de sua maioria, sobre a importância do meio ambiente e sua conservação. Além do entendimento sobre a relação homennatureza, fato esse de extrema importância quando se trata de desenvolvimento sustentável.

Podemos ressaltar ainda, que devido a variabilidade na formatação das atividades e a forma lúdica que elas foram trabalhadas levou os alunos, não só a aprendizagem, mas também a um maior espírito de cooperação em grupo, o que é bom para o cotidiano, já que devemos nos adaptar a trabalhar com diferentes pessoas em diferentes situaçoes.

Por outro lado, podemos dizer que a temática trabalhada nesse projeto necessita ganhar mais destaque e um trabalho contínuo para a maior e melhor conscientização de toda população, em específico os estudantes, isso porque participação em projetos de educação ambiental disponibiliza aos alunos ferramentas para uma maior reflexão sobre os seus atos, pois propicia uma abordagem global e interdisciplinar de problemas, o que acarreta na compreensão da importância dos valores de solidariedade e cooperação, ajudando-os também a definir o seu lugar e seu papel na natureza.

\section{Referências}

ANTUNES, C. Manual de técnicas de dinâmica de grupo de sensibilização de ludopedagogia. 10. ed. Petrópolis: Vozes, 1996. 190 p.

BOVO, M. C. Desenvolvimento da educação ambiental na vida escolar: avanços e desafios. Revista Urutágua, Maringá, n. 13, set./out./nov./dez. 2007. 
GOLDEMBERG, J.; LUCON, O. Energia e Meio Ambiente no Brasil. Estudos Avançados, São Paulo, n.21, v.59, 2007.

GUIMARÃES, M. Intervenção educacional. In: FERRARO JÚNIOR, L. A. (Org.). Encontros e caminhos: formação de educadoras (es) ambientais e coletivos educadores. 1ed. Brasília: MMA. Diretoria de Educação Ambiental. 2005. 358p.

JACOBI, P. Educação ambiental, cidadania e sustentabilidade. Cadernos de Pesquisa, São Paulo, n. 118, mar., 2003.

JACOBI, P. Educação ambiental e o desafio da sustentabilidade socioambiental. O Mundo Da Saúde São Paulo. São Paulo, v. 30. n. 5, out/dez, 2006.

SATO, M. Educação Ambiental. 1ed. São Carlos: RiMa. 2004. 68p.

LIMA, M. R. A Reciclagem do Papel no Processo Ensino-Aprendizagem (Ensino Fundamental). 2007, 27f. Monografia (Especialização em Geografia do Brasil) - Faculdades Integradas de Jacarepaguá, Rio de Janeiro, 2007.

MARQUES, S. Energias Fósseis versus Energias Renováveis: proposta de intervenção de Educação Ambiental no $1^{\circ}$ Ciclo do Ensino Básico. 2007. 241f. Dissertação (Mestrado em Estudos da Criança Promoção da Saúde e do Meio Ambiente) - Instituto de Estudos da Criança, Universidade do Minho, Braga, 2007.

MORAES, R. Mergulhos Discursivos análise textual qualitativa entendida como processo integrado de aprender, comunicar e interferir em discursos. In: FREITAS, J. V.; GALIAZZI, M. C. (Orgs.). Metodologia emergente de pesquisa em Educação Ambiental, Coleção e Educação em Ciências, ed. Unijuí, p. 84-115, 2007.

MORENO, C. H. C. Rendimento da reação de transesterificação, na produção de biodiesel, a partir de diferentes relações molares álcool-óleo e temperatura de reação. 2007. 71 f. Trabalho de Graduação (Bacharelado em Agronomia) - Faculdade de Engenharia, Universidade Estadual Paulista, Ilha Solteira, 2007. p. 06-08.

OLIVEIRA, J. A. B.; AQUINO, K. A. S. Óleo Residual de Frituras: Impactos Ambientais, Educação e Sustentabilidade no Biodiesel e Sabão. In: Jornada De Ensino, Pesquisa e Extensão, 10., 2010. Recife. Anais... Recife: EFRPE, 2010, 3p. 